\title{
Jesaja 40:1-2 - Suiwer evangelie!
}

\author{
A A da Silva \\ Universiteit van Pretoria
}

\begin{abstract}
Isaiah 40:1-2 - Pure gospel!

This article endeavours to analize Isaiah $40: 1-2$ in such a way that ministers who are experiencing difficulties in preaching the Old Testament might find in it some guidelines on a workable way in which sections of the Old Testament could be analized with the purpose of making a sermon about it. The method employed consists of four steps, namely a general orientation, a synchronic analysis, a diachronic analysis and a reception-critical analysis. The results show that Isaiah 40:1-2 is pure gospel! It speaks in no way less than the New Testament about God's redemption of the sinner through his grace alone!
\end{abstract}

\section{INLEIDING}

Die bedoeling met hierdie artikel is om Jesaja 40:1-2 op so 'n wyse te eksegetiseer dat dit vir predikante wat dit moeilik vind om oor die Ou Testament te preek, sekere riglyne sal bied oor 'n werkbare wyse waarop gedeeltes uit die Ou Testament benader, ontleed en verstaan kan word, met die oog op die maak van 'n preek daaroor.

Die feit dat hierdie artikel gemik is op die praktyk, hou noodwendig sekere gevolge in vir die metode wat gevolg sal word.

By sommige fasette van die metode sal die klem uiteraard gele word op 'n streng wetenskaplike hantering van die teks. Hieronder val byvoorbeeld: die sinchroniese analise met stappe soos teksafbakening, tekskritiek en struktuuranalises; die diachroniese analise, wat insluit stappe soos 'Gattung'-kritiek, motiefkritiek, tradisiekritiek en redaksiekritiek; en 'n deel van die resepsie-kritiese analise waarin daar gekyk word na die wyse waarop verskeie kommentatore reeds in húlle kommunikasie met die teks sekere betekenisse aan die teks 'toegeken het'. Hier lê die klem op kontrole. 
By ander fasette van die metode sal daar meer ruimte gelaat word vir die eksegeet se persoonlike benadering en voorkeure. Hier word byvoorbeeld gedink aan fasette en stappe soos: die voorlopige oriëntering, wat insluit die lees van die gekose teksgedeelte in een of meer vertalings, en die lees van die teks in Hebreeus daarna; aspekte van die sinchroniese analise, wat insluit die voorlopige vertaling' van die teks in Afrikaans, en die oorweging van die verskillende 'strukture' wat daar moontlik in die teks aangewys kan word; en 'n deel van die resepsie-kritiese analise waarmee 'n eie poging aangewend word om 'betekenis aan die teks toe te ken'.

Dat daar ruimte gelaat word vir persoonlike benadering en voorkeure beteken egter nie 'n vrypas tot willekeur nie. Ook by hierdie stappe van die metode sal die eis geld dat alle resultate 'voorlopig sal bly' totdat dit deur resultate van die ander stappe gekontroleer of bevestig word.

Die eksegese van die gekose gedeelte sal soos volg verloop: Daar sal telkens by die behandeling van die onderskeie fasette en stappe gesê word wat die doel van daardie spesifieke faset of stap is. Waar nodig, sal verduidelik word hoe 'n sekere stap uitgevoer moet word. En laastens sal by die samevatting van die resultate aangedui word:

- watter bydrae daardie spesifieke eksegetiese stap gemaak het tot die verstaan van die inhoud en die betekenis van die gekose teksgedeelte;

- of dit enige aanduidings gee van werk wat nog aan die teks gedoen moet word; en

- of dit enige van die resultate van die voorafgaande stappe bevestig of weerspreek.

Met die gebruik van hierdie metode word geensins gesuggereer dat dit 'beter' as ander eksegetiese metodes is nie. Die redes vir hierdie keuse is omdat dit 'n metode is waarvan die stappe logies op mekaar voortbou en mekaar onderling kontroleer, en omdat dit vir die eksegeet met min tyd tot sy beskikking, 'n bondige, werkbare metode bied wat, afhangende die aard van die teks, aangepas, verkort of uitgebrei kan word.

\section{ALGEMENE ORIËNTERING}

Die doel van hierdie faset is om die eksegeet vertroud te maak met die teks wat ontleed sal word. Deur gewoonweg net die teks deur te lees, en sekere inhoude daarvan waar te neem sonder om dit wetenskaplik te probeer kontroleer, verkry die eksegeet 'n vertroudheid met die teks wat sy latere, streng wetenskaplike omgaan met die 
teks positief sal beïnvloed.

2.1 'n Voorlopige kennisname van die inhoud van die teks

As eerste stap moet die gedeelte wat ontleed word (in hierdie geval Jes 40:1-2), binne sy onmiddellike konteks (Jes 39; Jes 40:1-26) 'n paar keer aandagtig in een of meer vertalings deurgelees word.

Vanaf die tweede deurlees moet daar gedurig gevra word: 'Wat staan hier geskrywe?', sodat bewustelik kennis geneem kan word van die verskillende inhoude, en van die groepering van gedagtes in kleiner eenhede.

Uiteindelik moet gepoog word om 'n beeld te vorm van die breë opbou van die gedeeltes waarbinne Jesaja 40:1-2 voorkom. Hier sal veral gevra moet word: 'Wáar pas Jesaja 40:1-2 die beste in - by die stuk wat dit voorafgaan, of by die stuk wat daarop volg?', en 'hot pas dit daar in?'.

\section{Resultaat}

Die eerste resultaat is ' $n$ algemene indruk van sowel die inhoud van Jesaja 40:1-2, as die konteks waarbinne dit voorkom. Reeds hiér kan die eksegeet sê: Jesaja 40:1.2 handel onder andere oor troos en oor die vryskelding van skuld; en dit is waarskynlik die begin van ' $n$ nuwe eenheid wat verskil van die eenheid wat by Jesaja 39:8 tot 'n einde kom.

\section{Vertroudraak met die Hebreeuse teks}

Nadat daar deur middel van die vertalings 'n algemene indruk verkry is van die inhoud van Jesaja 40:1-2, moet, met die vertalings as sleutel en met 'n woordeboek as hulpmiddel, die Hebreeuse teks van Jesaja 40:1-2 gelees word.

Daar is ' $n$ goeie rede waarom ' $n$ eksegeet nie ' $n$ eksegese van slegs ' $n$ vertaling behoort te maak nie. 'n Vertaling, hoe goed dit ook al is, is maar net én van 'n hele aantal moontlike interpretasies van wat daar in die Hebreeus geskryf staan. En as die eksegeet met $s 6$ ' $n$ eksegese sou volstaan, is sy 'eksegese' slegs ' $n$ interpretasie van ' $n$ interpretasie, en stel hy homself bloot aan die gevaar van eensydigheid, onvolledigheid en vervlakking. As 'n eksegeet dus wil poog om 'n diepgaande eksegese van 'n Ou-Testamentiese teks te maak, sal hy nie anders kan as om met die Hebreeuse teks te werk nie.

\section{Resultaat}

Hoewel die eksegeet met hierdie stap waarskynlik nie sy algemene indruk van die inhoud van Jesaja 40:1-2 verbeter het nie, sal hy ná die lees van die teks in Hebreeus:

- wét dat die stuk Hebreeuse poèsie is wat as sodanig benader sal moet word; en 
- besef dat daar in die stuk onbekende woorde en vorme is wat in 'n woordeboek nageslaan en volledig ontleed sal moet word.

\section{SINCHRONIESE ANALISE}

Die tweede faset van hierdie eksegetiese metode maak erns met die feit dat 'n OuTestamentiese teks literatuur is, en dat die teks daarom volgens letterkundige (d w s grammatikale, sintaktiese, poêtiese en semantiese) maatstawwe ondersoek moet word. Die doel met hierdie faset is: (a) om die eksegeet in staat te stel om die teks binne sy taalkundige konteks te ontleed; en (b) om verder, uit die 'betekenis' wat op só 'n wyse blootgelê word, alreeds sekere inligting af te lei oor die teologie van die perikoop.

Die stappe van hierdie faset is soos volg:

\subsection{Teksafbakening}

\subsubsection{Doel}

Die doel van 'n teksafbakening is om 'n identifikasie te maak van 'n afgeronde groep verbandhoudende sinne wat as 'n klein, selfstandige literêre eenheid ('n perikoop) sinvol ontleed kan word.

\subsubsection{Maatstawwe}

Die maatstawwe waarvolgens hierdie afbakening gedoen word, is onder andere die volgende:

- inleidings- en slotformules;

- subjekwisselings;

- konsentrasie van woorde of woordgroepe;

- afwisselings van prosa en poësie;

- sintaktiese merkers;

- kommunikatiewe middele; en

- tipiese struktuurelemente.

Hoewel inhoudelike elemente ook soms gebruik word vir die afbakening van perikope, dra hulle minder gewig as bogenoemde formele kriteria, en funksioneer hulle bloot as addisionele argumente. 


\subsubsection{Afbakening van Jesaja 40:1-2}

Wanneer die verse van Jesaja 40:1-2 aan die hand van bogenoemde kriteria beskou word in hulle verhouding tot mekaar, asook in hulle verhouding tot die vers direk vooraf (Jes 39:8), en tot die vers direk daarna (Jes 40:3), blyk die volgende:

- Verse 40:1 en 40:2 vorm 'n afgeronde groep verbandhoudende sinne wat as eenheid selfstandig kan funksioneer.

Die redes hiervoor is die volgende: Die subjek van die sin wat oor beide verse loop, is Jahwe; in beide verse is daar twee opdragte aan ongeïdentifiseerde persone; en in beide verse is die voorwerp op wie die opdragte gemik is, God se volk.

- Verse 39:8 en 40:1 kan van mekaar afgegrens word op grond van 'n wisseling van prosa na poësie; 'n subjekwisseling (Hiskia in 39:8 en Jahwe in 40:1); verskille in struktuurelemente (die elemente van 'n vertelling in 39:8 en die elemente van 'n oproep in 40:1); en inhoudelike elemente (soos 'n saak en tyd wat verskil).

- Verse 40:2 en 40:3 kan van mekaar afgegrens word op grond van: 'n subjekwisseling (Jahwe in 40:1-2 en 'n 'stem' in 40:3); konsentrasie van woorde uit verskillende betekenisvelde ('sonde'-aanduidings in 40:2 en 'plek'-aanduidings in 40:3); en inhoudelike elemente ('n opdrag om God se volk te troos in 40:2, en 'n opdrag om 'n pad vir die Here voor te berei in 40:3).

\subsubsection{Resultate}

Nadat Jesaja 40:1-2 getoets is aan die hand van bogenoemde kriteria, is die volgende resultate verkry:

- Die eksegeet het genoegsame gronde gevind om Jesaja 40:1-2 te beskou as 'n afgeronde eenheid;

- Omdat dit so 'n klein eenheid is, kan dit maklik ontleed word; en

- Omdat sekere aspekte van hierdie eenheid tydens die afbakeningsproses met aspekte van die omliggende verse vergelyk is, het die eksegeet alreeds dáardeur meer te wete gekom van die aard en die inhoud van die eenheid self. Die eksegeet kan ná hierdie arbeid al sê: dit gaan in hierdie perikoop om opdragte van God aan mense wat nie geïdentifiseer word nie, om aan sy volk 'n blye boodskap te bring. 


\subsection{Tekskritiek}

\subsubsection{Doel}

Die doel van tekskritiek is om die mees outentieke teks vas te stel. Om dit te kan doen sal die eksegeet aan die hand van 'n aantal aanvaarde tekskritiese kriteria moet nagaan of daar enige foute by ' $n$ teks ingesluip het nadat dit reeds sy finale vorm bereik het; en verder moet poog om sulke foute waar moontlik, reg te stel. Omdat hierdie stap baie tegniese vaardigheid vereis, is die raadpleeg van kommentare op hierdie stadium uiters noodsaaklik.

\section{2 .2 Tekskritiese beoordeling van Jesaja 40:1-2}

Nadat die teks van Jesaja 40:1-2 met die hulp van 'n paar kommentare tekskrities ondersoek is, is bevind dat dit geen taalkundige probleme oplewer nie.

\subsubsection{Resultaat}

Die feit dat die teks van Jesaja 40:1-2 geen taalkundige probleme ventoon nie, lewer nie vir die eksegeet ' $n$ onmiddellike bydrae tot ' $n$ beter verstaan van die inhoud van die teks nie. Tog het dit die voordeel dat die eksegeet nou presies weet hoe die teks hyk waarmee hy in gesprek gaan tree.

\section{3 'n Voorlopige vertaling}

\subsubsection{Doel}

$\mathrm{Na}$ die afhandeling van die teksafbakening en die tekskritiek kry die eksegeet nou die geleentheid om sy 'eintlike gesprek met die teks' te begin. Hy sal, waar nodig, woorde grammatikaal moet ontleed; daarna sal hy die Hebreeuse sinne sintakties moet analiseer; en laastens sal hy, op grond van sy ontledingsresultate, moet poog om die Hebreeuse teks in eenvoudige, verstaanbare Afrikaans te vertaal. Twee vereistes is hier van baie groot belang: (a) dat die vertaling teksgetrou moet wees; en (b) dat baie goed besef moet word dat so 'n vertaling slegs voorlopig van aard is. Dit kan nie op hierdie stadium die finale vertaling wees nie, en dit mag ook nie die resultate van die eksegese vooruitloop nie.

\subsection{2 in Voorlopige vertaling van Jesaja 40:1-2}

Nadat die teks van Jesaja 40:1-2

- grammutikaal ontleed is ( $\mathrm{d} w \mathrm{~s}$, alle moeilike vorme volledig verklaar is, en die betekenismoontlikhede van alle onbekende woorde in 'n woordeboek opgesoek 
is); en

- sintakties geanaliseer is ( $\mathrm{d} w \mathrm{~s}$, die verbande tussen die woorde en die sinne van die stuk onderling vasgestel is),

is die volgende teksgetroue vertaling daarvan gemaak in eenvoudige, verstaanbare Afrikaans:

40:1 Troos!'

'Troos my volk!' sê julle God -

40.2 'Praat ernstig met Jerusalem';

'En verseker hom:

- dat hy sy stryd (diensplig) voltooi het;

- dat sy skuld betaal is;

- dat hy uit die hand van die Here 'n dubbele straf ontvang het vir al sy oortredinge.'

\subsubsection{Resultaat}

Met die maak van hierdie voorlopige vertaling is die volgende resultate verkry:

- Inligting oor die inhoud van Jesaja 40:1-2 wat tot dusver fragmentaries en ongeordend was, is aangevul en geordend in ' $n$ voorlopige vertaling saamgevat. Die eksegeet kan nou sê: Waar ek op grond van die vorige stappe se resultate nog net geweet het dat dit in Jesaja 40:1-2 gaan om 'troos', om 'opdragte van God', en om 'die vryskelding van skuld', daar kan ek noú ook sê dat die stuk oor twee stelle opdragte van God handel. In die eerste stel beveel God 'n groep ongeidentifiseerde gestuurdes om sy volk te gaan troos. In die tweede stel beveel Hy hulle om vir sy volk te sê dat sy swaarkry verby is omdat God hom ál sy oortredinge vergewe het.

- Met die grammatikale en die sintaktiese analises van Jesaja 40:1-2 is daar 'n hoeveelheid taalkundige inligting bekom wat baie nuttig aangewend kan word in die volgende eksegetiese stap, naamlik die maak van twee struktuuranalises van die stuk.

3.4 Struktuuranalises

\subsubsection{Doel}

'n Struktuuranalise bestaan uit twee fasette: die eerste is 'n grafiese voorstelling 
( $\mathrm{m} v$ 'n stelsel van hakies, verbindingslyne en nommering) van die verskillende sintaktiese, semantiese en stilistiese verbande wat aangetoon kan word in die geskrewe vorm (die oppervlakstruktuur) van die teks. Die tweede faset is 'n toeligting van die grafiese voorstelling deur middel van ' $n$ wetenskaplike beskrywing van die aard en funksie van elkeen van die geìdentifiseerde verbande.

Die doel van so 'n struktuuranalise is om op ' $n$ gekontroleerde wyse te beweeg van die oppervlakstruktuur na die dieptestruktuur van 'n teks, of om dit eenvoudiger te stel: om deur die ontsyfering van die kommunikasiekodes van 'n teks vas te stel wat daar staan, hoe dit inmekaar pas en wat die fokuspunt is.

Dit beteken egter nie dat die waarde van ' $n$ struktuuranalise oorskat moet word nie. 'n Struktuuranalise is slegs éen van 'n hele aantal stappe van 'n multidimensionele eksegetiese metode, en soos al die ander stappe dra dit hoogstens 'n deel by tot die verstaan van die boodskap van die teks. Wat meer is: 'n struktuuranalise van 'n teks is nie dié struktuuranalise van daardie teks nie. Omdat Hebreeuse tekste soms dubbelsinnig verklaar kan word, en omdat elke eksegeet subjektief na ' $n$ teks kyk, kán daar meer as een geldige struktuuranalise van 'n teks gemaak word. 'n Struktuuranalise is en bly slegs ' $n$ hulpmiddel te midde van baie ander, en die resultate daarvan moet net soos dié van enige ander eksegetiese stap gekontroleer word.

\subsection{2 'n Sintaktiese struktuuranalise van Jesaja 40:1-2}

Voordat daar gekyk word na 'n stigometriese analise van Jesaja 40:1-2 as 'n stuk poësie, word daar eers stilgestaan by 'n sintaktiese struktuuranalise daarvan, omdat dit net soos prosa gestruktureerde taal is wat aan die eise van die sintaksis moet voldoen.

Die grafiese voorstelling van 'n sintaktiese struktuuranalise van Jesaja 40:1-2 lyk soos volg: 


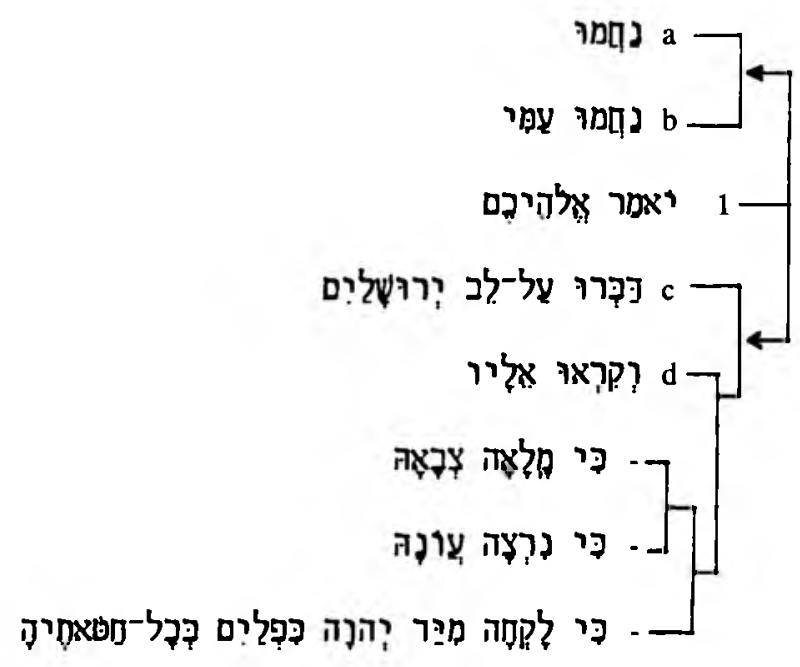

In die grafiese voorstelling hierbo word die volgende verbande aangetoon:

- Die stuk bestaan uit slegs één hoofsin - 'n stelsin - met 'n 'werkwoord van sè', en met Jahwe as die Subjek daarvan.

- Ingebed by hierdie enkele hoofsin met sy 'werkwoord van sê', is daar vier sinne in die direkte rede - al vier bevelsinne - waarvan die eerste twee voór en die laaste twee ná die hoofsin voorkom.

- Slegs die laaste van die vier ingebedde bevelsinne is uitgebrei deur middel van drie objeksinne, ingelui deur die partikel $\mathrm{Y}$ ?

- Die objeksinne bevat die inhoud van Jahwe se boodskap aan sy volk.

\subsubsection{Resultate}

Die resultate wat uit hierdie sintaktiese struktuuranalise van Jesaja 40:1-2 voortvloei, is tweeledig:

- Eerstens bevestig dit op 'n gekontroleerde wyse die insigte wat reeds verkry is uit die maak van die voorlopige vertaling; en

- tweedens beklemtoon die struktuur van die stuk die feit dat al die opdragte wat daarin voorkom, opdragte van God is. 


\subsection{4 'n Stigometriese struktuuranalise van Jesaja 40:1-2}

Omdat Jesaja 40:1-2 Hebreeuse poësie is, is die teks vervolgens stigometries gerangskik, en is daar gepoog om die poëtiese kommunikatiewe middele en die stilistiese verbande wat daarin voorkom, te identifiseer en die funksies daarvan te beskryf.

Die grafiese voorstelling van 'n stigometriese struktuuranalise van Jesaja 40:1-2 lyk soos volg:

3

2

3

2

3

3

4

2
3
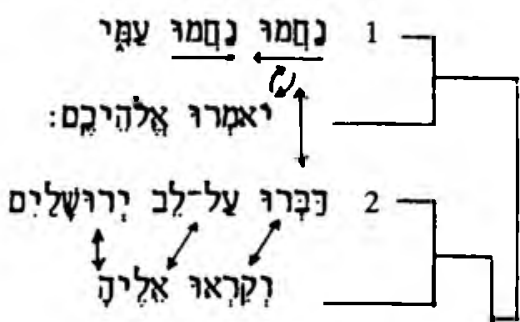

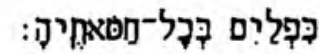

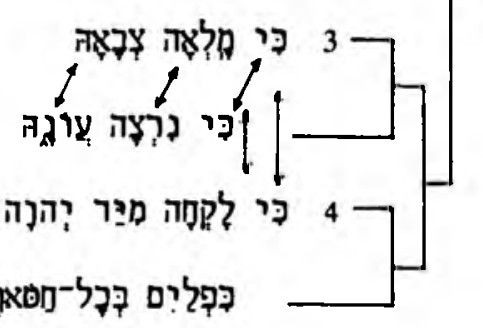

Uit bogenoemde grafiese voorstelling blyk dit dat die digter van die volgende tegnieke en verbande gebruik gemaak het om sekere sake voorop te stel of te beklemtoon:

- Afwykende grammatika:

- In stige 1 is die normale Hebreeuse woordorde omgekeer deurdat twee afhanklike, ingebedde sinne voor die hoofsin geplaas is.

Met hierdie vooropstelling is die dringendheid van die opdrag om te troos, sterk beklemtoon.

- Ekstra patroonvorming:

- In stige 1 word dieselfde bevelsvorm herhaal; daar is 'n duidelike assonansie tussen die eerste woorde van stiges 1 en 2 ; en daar is 'n parallelisme 
in stige 2.

Met al hierdie herhalingstegnieke word nog verdere klem gelê op die dringendheid van die opdrag om God se volk te troos.

- Daar is 'n volledige parallelisme tussen die versbene van stige 3.

Hiermee word waarskynlik die volledigheid van die volk se verlossing beklemtoon.

- En ten slotte is daar ' $n$ parallelisme met klankspel en rym tussen versbene $3 a$ en $4 a$.

Hiermee wou die digter waarskynlik opsommend beklemtoon dat die volk se skuld voor Jahwe ten volle vereffen is.

\subsubsection{Resultate}

Die insig wat reeds verkry is uit die voorlopige vertaling, is daarná bevestig deur die sintaktiese struktuuranalise. Hierdie insig kom daarop neer dat die opdragte in Jesaja 40:1-2 belangrik is omdat hulle van God af kom. Hierbenewens volg ook nó uit die resultate van die stigometriese struktuuranalise die verdere insig dat die digter waarskynlik sy poësie dólbewus op so' 'n wyse gerangskik het dat hy tweé dinge daarmee baie sterk wou beklemtoon:

eerstens - dat die opdragte om te troos en 'n blye boodskap te bring, uiters dringend was!

tweedens - dat die inhoud van die troosboodskap ' $\mathrm{n}$ vólle vryskelding van skuld en 'n totale verlossing uit nood is.

\section{DIACHRONIESE ANAIUSE}

Die derde faset van hierdie eksegetiese metode, naamlik die diachroniese analise, maak erns met die feit dat die teks deel is van 'n groter geheel en dat dit 'n sekere historiese ontwikkeling ondergaan het.

Die doel van so 'n diachroniese analise is: (a) om die eksegeet in staat te stel om die betekenis van die perikoop in 'n wyer literêre asook historiese konteks vas te stel; en (b) om uit die 'betekenis' wat op só 'n wyse blootgelê word, nog verdere inligting te bekom oor 'die teologie van die perikoop' binne die konteks van 'die teologieë van die Ou Testament' as geheel. 
By hierdie faset sal meer as by enige vorige eksegetiese stap gesteun word op inligting uit kommentare, teologiese woordeboeke, ensovoorts. Die stappe van hierdie faset is soos volg:

\subsection{Gattung-kritick}

\subsubsection{Doel}

Elke literêre genre funksioneer binne 'n spesifieke kultuur-historiese konteks. Daarom is die doel van hierdie eksegetiese stap: (a) om, indien moontlik, 'n perikoop as een van die literêre genres van die Ou Testament te tipeer, en (b) om sodoende meer te probeer agterkom oor die kultuur-historiese konteks waarbinne die teks gefunksioneer het (die teks se 'Sitz im Leben'). Omdat hierdie stap tegnies baie moeilik is, word aanbeveel dat daar oor hierdie aspek soveel moontlik kommentare en teologiese woordeboeke geraadpleeg word.

\subsubsection{Bepaling van die literere genre van Jesaja 40:1-2}

Om Jesaja 40:1-2 as literêre genre te probeer tipeer, is die perikoop vergelyk met soortgelyke stukke uit litererronafhanklike boeke van die Ou Testament. So is daar byvoorbeeld gevind dat Jesaja 40:1-2 die volgende sterk ooreenkomste vertoon met gedeeltes soos Jeremia 30:3; 30:18-20; 32:37-38 en Esegiël 37:4-7:

- In elke gedeelte gee Jahwe opdragte om aan sy volk 'n troosboodskap te bring.

- In elkeen is daar sprake van skuldvergifnis.

- In elkeen is daar, eksplisiet of implisiet, 'n belofte van herstel aan die volk wat op daardie stadium nog in ballingskap verkeer.

\subsection{Resultaat}

Op grond van bogenoemde bevindinge kan Jesaja 40:1-2 beskryf word as 'n 'profetiese heilsboodskap met 'n belofte van herstel'. As die teks se 'Sitz im Leben' in ag geneem word, $k a n$ verder afgelei word dat die bedoeling met hierdie heilsboodskap waarsknlik was om diegene onder die volk wat besig was om moed te verloor, nuwe hoop te gee, en dié wat verslae was, se vertroue op God te herstel.

\subsection{Motief- en tradisiekritiek}

\subsubsection{Doel}

Teksgedeeltes bevat dikwels verwysings na sekere teologiese motiewe (soos die liefde van God, die verganklikheid van die mens, ens), en sekere historiese tradisies 
(soos die skeppingstradisies, die uittogtradisie, die Sinaïtradisie, die landinnametradisie, ens).

Omdat verwysings hierna kan help om 'n teksgedeelte binne 'n sekere historiesteologiese konteks te plaas, is die doel van hierdie stap om sulke venwysings te identifiseer, te ontleed, en te probeer vasstel hoe hulle in die teks funksioneer sodat daardeur gekom kan word tot ' $n$ nog beter verstaan van die betekenis van die teks.

\subsection{2 'n Ondersoek na motiewe en tradisies in Jesaja 40:1-2}

Nadat die teks van Jesaja 40:1-2 ondersoek is vir verwysings na geykte motiewe en na Israel se geskiedenistradisies, is gevind dat daar van motiewe en tradisies in die ware sin van die woord in Jesaja 40:1-2 nie sprake is nie.

Van beeldryke taal is daar wel sprake. So is daar byvoorbeeld in stige 2 ' $n$ verwysing na die han van Jerusalem, wat in stige 4 gevolg word deur die antropomorfistiese verwysing na die hand van Jahwe. Hoewel sulke uitdrukkings in die idiomatiese vertaling van die Nuwe Afrikaanse Vertaling weggeval het ('...sê vir Jerusalem...hy het van die Here ontvang...'), bly dit tog 'n feit dat die digter sulke beelde doelbewus gebruik het om God se persoonlike bemoeienis met sy volk te onderstreep.

\subsubsection{Resultaat}

Daar is in Jesaja 40:1-2 geen verwysings na enige van Israel se historiese tradisies nie. Daar is egter wel 'n paar uitdrukkings wat sinspeel op ' $n$ intieme verhouding wat tussen God en sy volk bly voortbestaan het ten spyte van die volk se wegvoering in ballingskap.

\subsection{Redaksiekritiek}

\subsubsection{Doel}

Dit is soms moontlik, veral by lang perikope, om uit nate of oneffenhede in die teks af te lei dat verwerkers aan so 'n teks verander het, waarskynlik met die doel om sekere uitsprake duideliker te stel of selfs nuut te interpreteer.

As die aard en doel van sulke veranderings vasgestel kan word, kan dit ook bydra tot 'n nog beter verstaan van die teks.

Omdat so 'n ondersoek egter baie gespesialiseerde kennis vereis, is dit die veiligste om hieroor so veel moontlik goeie kommentare te raadpleeg, en om dan ook nog baie konserwatief te wees oor enige poging om die teks te herstel of te herinterpreteer. 


\subsection{2 'n Redaksie-kritiese ondersoek van Jesaja 40:1-2}

Aangesien daar in Jesaja 40:1-2 geen tekens is van enige veranderings of toevoegings nie, kan daar aanvaar word dat die teks, soos vasgestel tydens die afbakening, ' $n$ onveranderde eenheid is.

\section{RESEPSIE-KRTTIESE ANAIUSE}

Die laaste faset van hierdie besondere eksegetiese metode, naamlik die resepsiekritiese analise, maak erns met die feit dat die eksegeet 'n Nuwe-Testamentiese Christen-gelowige is wat vanuit 'n Christelike perspektief na die Ou Testament kyk.

\subsection{Besinning}

As die tese van die resepsiekritiek waar is, naamlik dat 'n teks eers betekenis kry as 'n leser sy kodes ontsyfer èn in die proses, as een van die medebepalende faktore van die kommunikasieproses, vanuit sy eie verstaan betekenis aan die teks 'toeken', hou dit vir die eksegeet 'n paar belangrike implikasies in:

- Hy sal eerstens moet seker maak dat sy ontsyfering van die teks se kodes op 'n wetenskaplik verantwoorde wyse gedoen is.

Uit die resultate van die onderskeie analises hierbo blyk dit dat daar reeds aan hierdie eis voldoen is.

- Hy sal tweedens moet sê vanuit watter vooronderstellings hy die teks lees.

Daarom sal hy rekening moet hou van die feit dat hy ' $n$ Christen-gelowige is wat vanuit 'n 'Christelike perspektief' na Jesaja 40:1-2 kyk. Hy kyk anders as 'n Jood of 'n Moslem, deúr die gebeure van die kruis heen, na die betekenis van Jesaja 40:1-2.

- Derdens sal hy moet uitspel watter betekenisse hy op grond van sy Christelike perspektief aan die stuk toeken, en hoe hy dit wetenskaplik verantwoord.

Hier kan een van twee weë gevolg word: of hy kan bloot sy eie bevindinge gee sonder inagneming van ander wetenskaplikes se insigte of hy kan ondersoek instel na die wyse waarop ander eksegete/kommentatore alreeds aan die teks 'betekenisse toegeken het', hulle metodes en resultate wetenskaplik weeg, vervolgens sê met watter gevolgtrekkings hy saamstem en met watter nie, en laastens byvoeg wat na sy oordeel nog kan bykom. 


\subsection{Die raadpleeg van kommentare}

Vir hierdie ondersoek is vyf kommentare geraadpleeg, naamlik die van Westermann (1969:31-36), Koole (1985:14-26), Beuken (1979:9-17), MacKenzie (1968:11-41) en Herbert (1975:15-21). In die beoordeling van elkeen se opvattings is gevind dat daar eenstemmigheid by hulle bestaan oor die volgende:

- dat Jesaja 40:1-2 ' $n$ heilsboodskap is wat bedoel is om ballinge in hulle nood te troos en te help;

- dat die boodskap bestaan uit 'n volle vryskelding van skuld voor God, en 'n vaste versekering van bevryding uit die nood van ballingskap;

- dat die identiteit van die gestuurdes met die boodskap doélbewus verswyg is sodat die inhoud van die boodskap, en die feit dat dit van God af kom, des te meer beklemtoon kan word;

- dat die stuk met uitdrukkings soos 'julle God' en 'my volk' herinner aan die intieme verhouding wat daar nog steeds bestaan tussen God en sy volk, die ballingskap ten spyt; en

- dat die vergifnis van skuld en die bevryding uit ballingskap te danke was aan die genade van God.

Daar kan om die volgende redes met al vyf gevolgtrekkings saamgestem word:

- Elkeen van hierdie gevolgtrekkings kan getoets word aan die gegewens in Jesaja 40:1-2, of aan die gegewens in die res van Jesaja 40-55 waarvan 40:1-2 die inleiding is.

- Elkeen adem die gees van die evangelie (redding uit genade alleen) sonder om énn ongeoorloofde verwysing na Christus of na die Nuwe Testament te maak.

\section{3 'n Eie betekenistoekenning}

Ou-Testamentiese eksegese, hoe deeglik of hoe wetenskaplik verantwoord dit ook al gedoen is, sal nutteloos wees as dit met die vorige stap sou eindig.

Eksegese van die Ou Testament is mér as net 'n vasstel van wat daar staan en wat dit beteken. Dit is $66 k$, en veral, ' $n$ vasstel van wat dit vir my beteken; hoe raak dit my in die daaglikse lewe wat duisende jare later ná die gebeure van die kruis daarna terugkyk?

As die eksegeet met hierdie vrae na die teks teruggaan, kry hy die volgende resultate: 
- Die teks vertel vir hom van mense soos hy: van sondaars wat as gevolg van hulle eie skuld in nood verkeer het.

- Die teks vertel verder vir hom hoe God met hierdie mense gehandel het. In plaas daarvan dat Hy hulle volledig verwerp het, noem Hy hulle nog 'my volk'; stuur Hy nog boodskappers na hulle; en sé nog vir hulle: 'Julle is vergewe' en 'Julle swaarkry is verby'.

Wat hierdie teks uniek maak, is die feit dat dit alreeds evangelie verkondig het (gepraat het van 'n redding uit genade) toe mense nog voluit gebuk gegaan het onder die harde uitsprake van die Joodse wysheid, naamlik dat goeie dade beloon word met seën, en dat ongehoorsaamheid en oortredinge noodwendig vergeld word met straf.

En as dit alles waar is, troos hierdie stuk nie net mense van lank gelede nie. Dit troos ook die eksegeet in sy daaglikse worsteling met die nood en die behoeftes van sy aardse bestaan en in sy voortdurende stryd teen die sonde. Dit sê vir hom: Jy mág tot God bid vir ál jou nood, konkreet en geestelik, God kán help en Hy wíl ook help. En dit verseker hom: die waarborg vir jou uitkoms lê in die hande van dié God wat nie net kán nie, maar wat réds vir jou verlossing betaal hét met die bloed van sy Seun, Jesus Christus, aan die kruis.

\section{Literatuurverwysings}

Beuken, W A M 1979. Jesaja Deel II A. Nijkerk: Callenbach. (POT 9-17.)

Herbert, A S 1975. The book of the prophet lsaiah Chapters 40-66. London:

Cambridge University Press, 15-21.

Koole, J L 1985. Jesaja II. Kampen: Kok. (COT.)

MacKenzie, J L 1968. Second Isaiah. New York: Doubleday. (The Anchor Bible.)

Westermann, C 1969. Isaiah 40-66: A commentary. Philadelphia: Westminster. 